\title{
Antibacterial Effects of Erbium Chromium Laser along with/ without Silver Nanoparticles in Root Canals Infected by Enterococcus faecalis
}

\author{
Seyedeh Sareh Hendi $\left(\mathbb{D},{ }^{1}\right.$ Negin Amiri, ${ }^{2}$ Banafsheh Poormoradi, ${ }^{3}$ \\ Mohammad Yousef Alikhani, ${ }^{4}$ Saeid Afshar, ${ }^{5}$ and Maryam Farhadian ${ }^{6}$ \\ ${ }^{1}$ Department of Endodontics, Dental School, Hamadan University of Medical Science, Hamadan, Iran \\ ${ }^{2}$ Hamadan University of Medical Sciences, Hamadan, Iran \\ ${ }^{3}$ Dental Research Center, Department of Periodontology, Dentistry Faculty, Hamadan University of Medical Sciences, \\ Hamadan, Iran \\ ${ }^{4}$ Microbiology Department, Faculty of Medicine, Hamadan University of Medical Science, Hamadan, Iran \\ ${ }^{5}$ Department of Molecular Medicine and Genetics, School of Advanced Technologies in Medicine, \\ Molecular Medicine Research Center, Hamadan University of Medical Sciences, Hamadan, Iran \\ ${ }^{6}$ Department of Biostatics, School of Public Health and Research Center for Health Sciences, \\ Hamadan University of Medical Science, Hamadan, Iran \\ Correspondence should be addressed to Seyedeh Sareh Hendi; hendispx@yahoo.com
}

Received 13 December 2020; Revised 1 March 2021; Accepted 21 March 2021; Published 8 April 2021

Academic Editor: Antonino Lo Giudice

Copyright (C) 2021 Seyedeh Sareh Hendi et al. This is an open access article distributed under the Creative Commons Attribution License, which permits unrestricted use, distribution, and reproduction in any medium, provided the original work is properly cited.

\begin{abstract}
This study investigates the antibacterial effects of erbium chromium laser at $2780 \mathrm{~nm}$, silver nanoparticles, and erbium chromium along with silver nanoparticles on Enterococcus faecalis in comparison with sodium hypochlorite. In the present study, 90 extracted human single-rooted teeth were selected and standardized to a length of $15 \mathrm{~mm}$. The canals were prepared by V-taper Gold rotary files and then incubated with E. faecalis for 21 days. The samples were divided into four experimental groups including hypochlorite sodium, silver nanoparticle, erbium chromium laser, and erbium chromium laser along with silver nanoparticle groups. Results showed that there was a significant reduction in colony count for all groups after interventions. Moreover, there was a significant reduction in the colony count for sodium hypochlorite group in comparison with another groups, and this group showed the highest reduction of colony count. There was a significant difference between silver nanoparticles and erbium chromium laser groups in colony count. According to the results, the silver nanoparticles offered strong antibacterial effects on E. faecalis and therefore can decrease bacterial colonies, while the use of the laser, despite the reduction of the bacterial colony, could not be sufficiently used for disinfection of root canal system.
\end{abstract}

\section{Introduction}

Enterococcus faecalis (E. faecalis) is a resistant bacterium that is able to live under various nutritional conditions. This bacterium has a high resistance to cleaning agents of root canal [1]. The main purpose of root canal treatment is to disinfect root canals and the three-dimensional structure of dentinal tubules [2-4]. Given the disadvantages of conventional root canal treatments, new methods such as lasers have received much attention from scientists in recent years.
Multiple laser systems can be used as auxiliary tools to promote root canal disinfection. In addition, laser beams can penetrate deeply into the dentinal tubules without being absorbed by the hard tooth tissue, leading to a reduction in the bacterial population by $63 \%$ at a depth of $750 \mu \mathrm{m}[5,6]$. The American Food and Drug Administration (FDA) has recommended the use of erbium chromium laser for cleaning and shaping the root canal space. The laser can remove hard calcified tissue by emitting infrared beams at a wavelength of $2780 \mathrm{~nm}$ in combination with water spray. 
The erbium chromium laser absorbs a lot of water and can adsorb the water inside and around tissues. Therefore, the Er, Cr : YSGG laser can be more effective in the presence of water $[7,8]$. Sodium hypochlorite is the most important material used in teeth root canal cleaning. Although it has many advantages, such as broad bactericidal spectrum and high ability for removing organic debris, but its antibacterial activity can be inactivated by the dentin or biological masses existing in the root canal, it needs to be frequently replaced and renewed. Moreover, root canal cleaning with sodium hypochlorite reduces the bond strength between dentin and resin $[9,10]$.

Silver nanoparticles have various medical applications due to their antibacterial and anti-inflammatory properties. The size of these particles ranges from 10 to $100 \mathrm{~nm}$ and they have antibacterial effects against Gram-negative and positive bacteria and also multidrug-resistant bacteria [10]. The mechanism of action of these particles is attributed to the release of silver ions, which are highly reactive and can react with the cell wall. The silver ions can form structural changes in the bacterium through the binding of these ions to tissue proteins $[10,11]$. Therefore, the use of silver nanoparticles has more antimicrobial effects over common medicines and disinfectants [12].

The root canal diseases are associated with pain, inflammation, and discomfort of the patient. On the other hand, E. faecalis is a resistant bacterium that causes recurrence and root canal infection. Therefore, the present study was aimed at introducing an efficient method to remove and eradicate this bacterium from root canal. In recent years, the effective role of silver nanoparticles on bacterial destruction and root canal cleaning has been investigated. Moreover, recent advances in the use of laser in dentistry have received much interest in the last couple of decades. In this regard, in the present study, we aimed to evaluate the antibacterial effects of silver nanoparticles along with erbium chromium laser at $2780 \mathrm{~nm}$ on E. faecalis existing in root canal.

\section{Materials and Methods}

2.1. Materials. The following materials were used: diamond disk (DFS Diamon Co., Germany) for removing the crown, K-files (Mani Inc., Japan), and rotary files (V-Taper Gold, Shanghai Fanta Dental, China) for preparation of the root canals. Normal saline (sodium chloride, 0.9\%) (Shahid ghazi Co., Tabriz, Iran), EDTA 17\% (Maraboon, Iran), and 5\% sodium hypochlorite (Paxan Co., Tehran, Iran) for irrigation of root canals. Eppendorf tube (Amin Co., Iran) and Acryle (Acropars Co., Iran) for fixing the roots. Standard strain of E. faecalis (ATCC29212), Trypticase soy broth; TSB (Hi-Media Laboratories, Mumbai, India), Tween 80 solution (Samchun Pure Chemical, Korea), PBS (Phosphate-buffered saline), and sheep blood agar plates (Hi-Media Laboratories, Mumbai, India) for microbiologic experiments. Sodium thiosulfate solution (Samchun Pure Chemical, Korea) for neutralizing sodium hypochlorite solution. ZetaSizer Nano ZS (ZEN3600) (Malvern, United Kingdom) for measuring Zeta potential. Erbium chromium laser (Biolase, Waterlase, USA).
2.2. Teeth Collection: Inclusion and Exclusion Criteria. The study was performed on 90 newly extracted single-canal human teeth and their single-canal was confirmed by radiography. The teeth were collected from comprehensive health centers. Sampling of single-canal anterior teeth was performed randomly based on the following inclusion criteria: teeth without any developmental defects, caries, and cracks or fractures. Moreover, nonaged teeth were selected to ensure that there is no dentin sclerosis and the calcified dental canal in the samples. Dental radiographs were taken to ensure that the selected teeth are single channel before operation, and teeth with curved roots were excluded.

2.3. Teeth Preparation. The samples were classified randomly into different treatment groups. In order to prepare the samples, their roots were cut at approximately $15 \mathrm{~mm}$ of apex using a diamond disk, and its working length was adjusted at $1 \mathrm{~mm}$ shorter than the apical foramen $(14 \mathrm{~mm})$. The root canals were first prepared up to No. 20 using manual K-files (Mani Inc, Japan), and 5\% sodium hypochlorite (Paxan Co., Tehran, Iran) then prepared by rotary files (V-Taper Gold, Shanghai Fanta Dental, China) to obtain the original file. During the use of rotary files, the canals were washed with normal saline (sodium chloride, $0.9 \%$ ) and 5\% sodium hypochlorite. After preparation with files, the canals were washed with $1 \mathrm{~mL}$ of $17 \%$ EDTA (Maraboon, Iran), $5 \mathrm{~mL}$ of normal saline, and $1 \mathrm{~mL}$ of $5 \%$ sodium hypochlorite and kept for $5 \mathrm{~min}$ in order to remove smear layer. Eventually, all canals were washed with $5 \mathrm{~mL}$ of normal saline. Afterwards, the roots of the teeth were fixed into a $2 \mathrm{~mL}$ microtube with acrylic (Acropars Co., Iran) and incubated at $121^{\circ} \mathrm{C}$ for 15 minutes [1].

2.4. Synthesis of AgPPENPs. To prepare silver nanoparticle suspension, pomegranate skin was dried in an oven at $50^{\circ} \mathrm{C}$ for 2 days, and to prepare the hydroalcoholic extract, $50 \mathrm{~g}$ of the pomegranate skin was soaked in $500 \mathrm{~mL}$ of alcohol (70\%) at room temperature for 72 hours. The extract of pomegranate powder was then extracted using Whitman No. 40 filter papers. In order to separate the fine suspended particles from the extract, a centrifuge was used. A certain amount of silver nitrate and the extract were dissolved in $200 \mathrm{~mL}$ of water to prepare the desired concentrations (100 and $200 \mathrm{ppm}$ ). The color of the solution changed from colorless to gray, which indicated the successful synthesis of AgPPENPs [13].

2.5. Cell Toxicity Assay of PPE and AgPPENPs. To examine potential toxicity of formulation, RMPI medium in $5 \%$ $\mathrm{CO}_{2}$ of atmosphere with the temperature of $37^{\circ} \mathrm{C}$ was used and fibroblast cell line L929 was cultured within. The cultured cells were exposed to different concentration of PPE and AgPPENPs (100, 200, 300, 400, and $500 \mu \mathrm{g} / \mathrm{mL}$ ). We used MTT assay to evaluate viability of the cells. The cells were cultured in 96-well plates and incubated for 3 hours with MTT solution. To solubilize formazan particles, DMSO solution was also added to each well and absorption rate was read using ELISA reader in $580 \mathrm{~nm}$. 
2.6. Bacterial Inoculation of Root Canals. The standard strain of $E$. faecalis (ATCC29212) was cultured in $5 \mathrm{~mL}$ of Trypticase soy broth, TSB (Hi-Media Laboratories, Mumbai, India) and incubated at $37^{\circ} \mathrm{C}$ for 24 hours and a concentration equivalent of $0.5 \mathrm{McF}$ arland standard from $\mathrm{E}$. faecalis $(1.5 \times 108 \mathrm{CFU} / \mathrm{mL})$ was provided. Then, $100 \mu \mathrm{L}$ of sterile TSB was added to the microtubule containing sterile tooth and 150 to $200 \mu \mathrm{L}$ of bacteria suspension $(1.5 \times 108 \mathrm{CFU} / \mathrm{mL})$ was added to microtubes containing teeth. $30 \mu \mathrm{L}$ of the culture containing about $10^{9}$ E. faecalis bacteria was added to the canals. The samples were then incubated at $37^{\circ} \mathrm{C}$ for 21 days to form biofilm. Every two days, $30 \mu \mathrm{L}$ of TSB suspension containing $E$. faecalis was removed from the canal and replaced with fresh sterile TSB under sterile conditions $[8,14]$. Congo red coloring was used for confirming biofilm formation.

2.7. Experimental Procedures. Group 1: cleaning with 5\% sodium hypochlorite: in this group, the root canal of the teeth was cleaned routinely with injecting $5 \mathrm{~mL}$ of $5 \%$ sodium hypochlorite solution (Snow, Paxan Co., Tehran, Iran) in apical third of canal (one or two $\mathrm{mm}$ from the foramen) using a $30-\mathrm{G}$ insulin syringe and kept in the canal for $5 \mathrm{~min}$. Then, $1 \mathrm{~mL}$ of $5 \%$ sodium thiosulfate solution (Samchun Pure Chemical, Korea) was injected into neutralize sodium hypochlorite solution and kept in the canal.

Group 2: cleaning with silver nanoparticles: the root canals were washed with $5 \mathrm{~mL}$ of the prepared silver nanoparticle suspension with a concentration of $100 \mathrm{ppm}$ (with mean particle size of $20 \mathrm{~nm}$ ). For this reason, an insulin syringe (Supa, Iran) was utilized and kept in the canal for $5 \mathrm{~min}$.

Group 3: using $2780 \mathrm{~nm}$ erbium chromium laser: the root canals of the teeth were cleaned using erbium chromium laser (Biolase, Waterlase, USA) at a wavelength of $2780 \mathrm{~nm}, 0.0 \%$ of water, $15 \%$ of air, and 75 watts of power. The power density was set at $2.5 \mathrm{watt} / \mathrm{cm}^{2}$ and energy density was equal to $25 \mathrm{~J} / \mathrm{cm}^{2}$. The laser head with a diameter of $200 \mu \mathrm{m}$ and $1 \mathrm{~mm}$ shorter than the apex (Biolase, Waterlase, USA, RFT2/Hmode) was used continuously with rotational and epicocoronal motions for $30 \mathrm{sec}$. This process was performed three times with an interval of $15 \mathrm{sec}$ between each laser irradiation.

Group 4: simultaneous use of erbium chromium laser and silver nanoparticles: in this group, the root canals were cleaned with $5 \mathrm{~mL}$ of the synthetized silver nanoparticles at a concentration of $100 \mathrm{ppm}$ (with mean particle size of $20 \mathrm{~nm}$ ) using an insulin syringe (Supa, Iran). After $5 \mathrm{~min}$, the erbium chromium laser with a wavelength of $2780 \mathrm{~nm}$ was applied for $30 \mathrm{sec}$, and this operation was conducted three times with an interval of $15 \mathrm{sec}$ between each irradiation similar to the group.

Group 5: negative control group (normal saline): root canals were washed with $5 \mathrm{~mL}$ normal saline using insulin syringe.

2.8. Initial Sampling. To standardize the bacterial prototype after the extraction of TSB and washing the canal with $5 \mathrm{ml}$ normal saline, root canals were filled with sterile saline solution using a $30-\mathrm{G}$ syringe, and dentin was scraped from inside the canals using a \#40 Hedstrom file (Mani Inc, Tochigi, Japan). A \#40 sterile paper point (Gapadent Co, Hamburg, Germany) was placed inside the canals for 60 seconds and was then transferred into a sterile microtube containing $1 \mathrm{~mL}$ Tween 80 solution (Samchun Pure Chemical, Korea) and vortexed for 20 seconds to isolate the bacterial biofilm. One hundred dilution was made from the first sample and cultured on blood agar medium and the plates were incubated at $37^{\circ} \mathrm{C}$ for $24 \mathrm{~h}$ and colony counts were reported according to $\mathrm{CFU} / \mathrm{mL}(8)$.

2.9. Final Sampling. To standardize all groups, the canals were washed with $5 \mathrm{~mL}$ of normal saline and the solution was kept in the root canal for $30 \mathrm{sec}$. Then, the sampling was performed in accordance with the primary sampling method and colony counts were reported according to CFU/mL.

2.10. Statistical Analysis. Accordingly, SPSS software (version 21) was utilized to analyze the data. For this purpose, the central dispersion indices for the number of live bacterial colonies were calculated and reported before and after the intervention. The decrease in bacterial colonies after the intervention in different groups was compared by Kruskal-Wallis nonparametric test. Moreover, changes in bacterial colonies before and after the intervention were recorded using Wilcoxon signed-rank test. Given the fact that the data were not in line with the normal distribution and presence of dispersed data in the colonies, nonparametric analyses were performed in the study. Type I error rate was set at $0.05(\alpha=0.05)$ [10].

\section{Results}

3.1. Properties of AgPPENPs. The mean of zeta potential for the nanoparticles at $\mathrm{pH}=7$ was $-28 \mathrm{mV}$.

TEM image results showed that the mean diameter of NPs was $20 \mathrm{~nm}$ (Figure 1).

3.2. X-Ray Diffraction of AgPPENPs. Figure 2 shows the XRD pattern of synthesized nanoparticles (AgPPENPs). Main peaks recorded at $2 \theta$ from $32.28,38.18,44.53,64.68$, and 77.58 are indexed as diffraction (111), (200), (220), and (311), respectively.

3.3. Cell Toxicity. To assess the potential toxicity of synthesized nanoparticles, cell viability assay was applied. The results pointed that AgPPENPs could decrease cell viability in the concentration of 400 and $500 \mu \mathrm{g} / \mathrm{mL}$, whereas PPE could decrease toxicity of the particles lonely, where the particles became completely safe in the concentration of $400 \mu \mathrm{g} / \mathrm{mL}$ without any remarkable toxicity (Figure 3).

3.4. Results. According to the results of Wilcoxon test, there was a significant decrease in the number of bacterial colonies after the intervention $(p<0.05)$. Table 1 and Figure 4 present descriptive values of $E$. faecalis colonies before and after the 


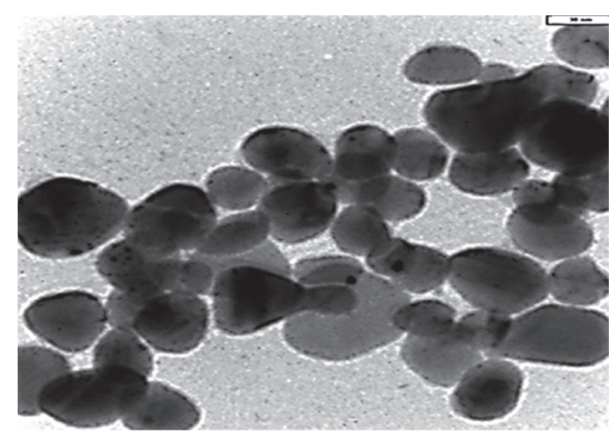

FIgURE 1: Transmission electron microscopy (TEM) image of the AgPPENPs (scale bar is $50 \mathrm{~nm}$ ).

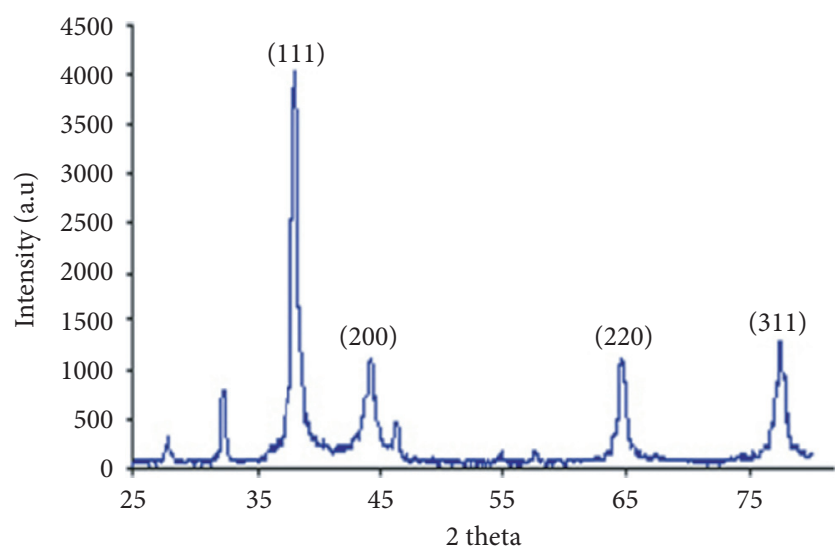

Figure 2: X-ray diffraction (XRD) pattern of AgPPENPs.

intervention and reduction percentage of colony count (RCC) in each studied group. The highest reduction percentage of E. faecalis colonies was observed in the sodium hypochlorite group, indicating that this disinfectant acted as the best disinfectant with an efficiency of $100 \%$, and the lowest decrease was observed in the erbium chromium laser group with an efficiency of $47.9 \%$.

Kruskal-Wallis test was used to compare the performance of different interventions with respect to the reduction percentage of bacterial colonies based on the mean values of the reduction of colony count (RCC). The results of this test showed that there was a significant difference between the reductions of bacterial colonies between different groups $(p=0.03)$.

Based on this result, Mann-Whitney test was used to compare the two groups. In most cases, the type I error rate $(\alpha)$ is considered to be 0.05 , but in the Mann-Whitney test by Bonferroni adjustment $\alpha$ was calculated according to the number of groups. In this study, according to the number of the groups (5 groups including four interventions and one control group), the value of $\alpha$ was calculated to be 0.005 . Therefore, the $p$ values less than 005 indicate a significant difference between the groups and the $p$ values greater than 0.005 indicate no significant difference between the groups (Table 2).

Results of Mann-Whitney test with Bonferroni adjustment showed that there was a significant difference between the sodium hypochlorite and silver nanoparticle groups with negative control group $(p<0.005)$, while the difference between the erbium chromium laser and erbium chromium laser along with silver nanoparticle groups with negative control group was not significantly different $(p>0.005)$. Moreover, there was a significant difference between the effect of sodium hypochlorite on reduction of bacterial colonies and other groups $(p<0.001)$. The erbium chromium laser along with silver nanoparticle group had no significant difference with negative control group $(p=0.102)$ and erbium chromium laser group ( $p=0.152)$. The erbium chromium laser group showed a lower effect compared with other groups. Also, there was no significant difference in the reduction of bacterial colonies between the silver nanoparticles group and silver nanoparticles along with erbium chromium laser group $(p=0.009)$.

\section{Discussion}

This study evaluated the antimicrobial effect of erbium chromium laser, silver nanoparticles, and their simultaneous applications on E. faecalis bacteria. Moreover, their effects were compared to sodium hypochlorite as the gold standard. The results showed that there was a significant decrease in the number of bacterial colonies between after and before using erbium chromium laser at $2780 \mathrm{~nm}\left(p_{\text {value }}<0.001\right)$. But the reduction percentage of bacterial colonies in the erbium chromium laser group was less than the sodium hypochlorite group $(\mathrm{RCC}=47.9)$. Also, the comparison of this group with the negative control group showed no significant difference ( $p_{\text {value }}=0.943$ ).

In Kasić et al.'s [14] study, the YSGG and Er : YAG lasers significantly reduced the number of microorganisms $(p<0.05)$. In the mentioned study, the high efficiency in the use of laser for cleaning root canal compared with the present study can be attributed to the rapid, turbulent, and mechanical movements of fluid inside the root canal, which facilitate the removal of the bacterial biofilm in root canal. The low efficiency of the erbium chromium laser in the present study can be related to the adsorption of laser power in the initial depth of dentin (at a depth of $400-300 \mu \mathrm{m}$ ). Also, in the present study, the dental canal was dried prior to laser irradiation by paper No. 40 , which can be considered as another probable reason for the low efficiency of laser application, because, in the mentioned study, during the irradiation of lasers of Er, Cr: YSGG and Er: YAG, $5 \mathrm{~mL}$ of saline was also injected by a 27 -gauge needle attached to a syringe with intra-canal pressure. In this study, the dental canal was dried with absorbent paper points (No. 40).

Due to the high absorption of erbium laser radiations by water and hydroxyapatite, and thus the reduction of the laser thermal effect, lasers are more efficient in the dried canals. In general, lasers such as erbium chromium laser can kill bacteria through their thermal effects. Therefore, the moisture can act as a reducing agent and subsequently reduces the lethal effect of lasers on bacteria [15].

According to the results of Wanda Gordon et al.'s study, the use of Er, Cr: YSGG laser at $240 \mathrm{~nm}$ and an exposure time of $240 \mathrm{sec}$ showed higher efficiency than sodium hypochlorite in dried root canal, which resulted in $99.7 \%$ 


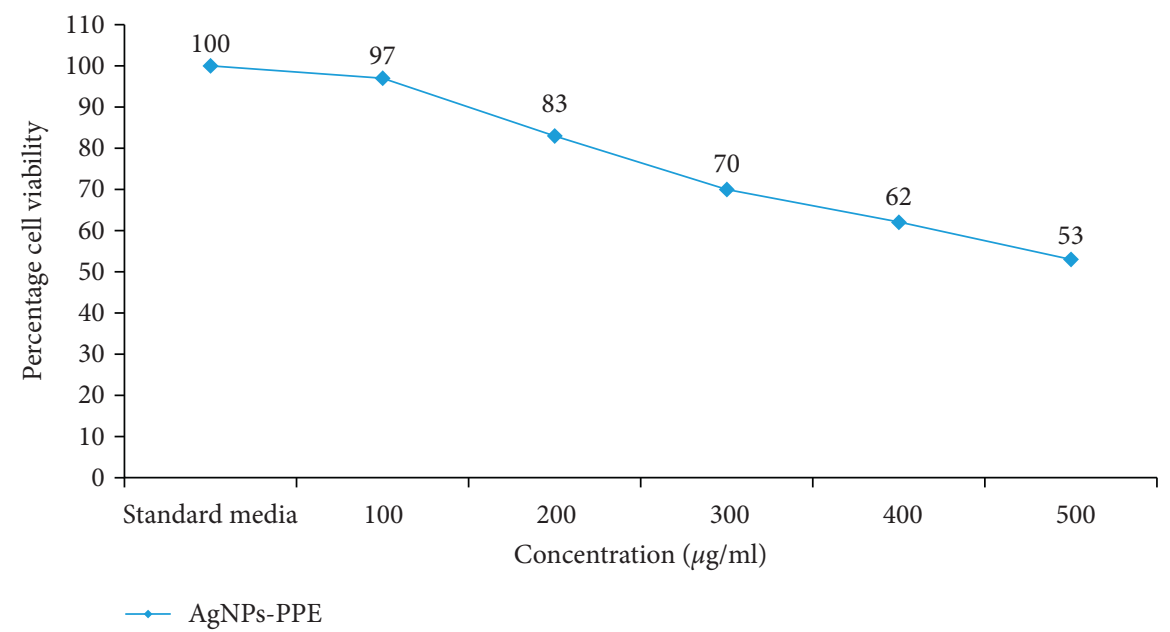

Figure 3: Cells viability of treatments with different concentrations of AgNPs-PPE and PPE after $48 \mathrm{hrs.}$

TABLE 1: Descriptive values of $E$. faecalis colonies before and after intervention and reduction percentage of bacterial colonies in each studied group.

\begin{tabular}{|c|c|c|c|c|c|}
\hline Groups & Time & Minimum & Maximum & RCC \% & $p$ value \\
\hline Sodium hypochlorite & $\begin{array}{l}\text { Before } \\
\text { After }\end{array}$ & $\begin{array}{c}10^{3} \times 12 \\
0\end{array}$ & $\begin{array}{c}10^{3} \times 27 \\
0\end{array}$ & 100 & $0.001>$ \\
\hline Silver nanoparticle & $\begin{array}{l}\text { Before } \\
\text { After }\end{array}$ & $\begin{array}{c}10^{3} \times 5 \\
0\end{array}$ & $\begin{array}{c}10^{3} \times 60 \\
10^{3} \times 8\end{array}$ & 83.15 & $0.001>$ \\
\hline Erbium chromium laser & $\begin{array}{l}\text { Before } \\
\text { After }\end{array}$ & $\begin{array}{c}10^{3} \times 11 \\
10^{3} \times 3\end{array}$ & $\begin{array}{l}10^{3} \times 36 \\
10^{3} \times 30\end{array}$ & 47.90 & $0.001>$ \\
\hline Silver nanoparticles and erbium chromium lasers & $\begin{array}{l}\text { Before } \\
\text { After }\end{array}$ & $\begin{array}{c}10^{3} \times 4 \\
0\end{array}$ & $\begin{array}{l}10^{3} \times 49 \\
10^{3} \times 13\end{array}$ & 64.72 & $0.001>$ \\
\hline Negative control (washing with normal saline) & $\begin{array}{l}\text { Before } \\
\text { After }\end{array}$ & $\begin{array}{c}10^{3} \times 3 \\
10^{3}\end{array}$ & $\begin{array}{l}10^{3} \times 58 \\
10^{3} \times 41\end{array}$ & 49 & $0.005>$ \\
\hline
\end{tabular}

${ }^{*}$ Wilcoxon test for determining significant differences in bacterial count before and after intervention.

reduction in bacterial count [7]. The difference between these results and the present study may be due to differences in the method used, because, in the mentioned study, dentin cylinders with a length and diameter of $5 \mathrm{~mm}$ were used, but in our study the root length was longer $(15 \mathrm{~mm})$ and radiation area was greater $(14 \mathrm{~mm})$. Laser light is emitted in a specific direction from the laser head or it is diverted from the straight direction by an angle of 18-20 degrees. The use of these inconsistent radiations makes it difficult to achieve a constant lighting condition in all dentinal surfaces of the root canal [16]. El-Gendy et al. reported that sodium hypochlorite had the highest bactericidal effect, which is consistent with our findings [17].

In Eldeniz et al.'s study, sodium hypochlorite was used in root canal for $15 \mathrm{~min}$, while in the present study this detergent was kept in canal for $5 \mathrm{~min}$. Given the toxic effects of sodium hypochlorite, it has been suggested to be used for short contact times in dental applications. In Eldeniz et al.'s [18] study, Er, Cr: YSGG laser showed much better efficiency than the control group ( $95 \%$ vs. $0 \%$ ), while, in our research, the bactericidal efficiency of normal saline in the control group (49\%) was higher than the erbium chromium in laser group at $2780 \mathrm{~nm}(47.9 \%)$ [19]. The better efficiency in the laser groups in Eldeniz et al.'s study may be due to the short inoculation time $(48 \mathrm{~h})$ in the root canal compared with 21 days in the present study, where the bacterial resistance to the cleaning agents increases with increasing the incubation time in the root canal and subsequently reduces the bactericidal effect of the used cleaning agents. In addition, in Eldeniz et al.'s study, the low efficiency in the control group can be attributed to receiving no treatment or intervention, whereas, in the present study, the control group received $5 \mathrm{~mL}$ of normal saline and washed for $5 \mathrm{~min}$.

The antimicrobial property of sodium hypochlorite depends on the concentration of unconjugated hypochlorous acid in the solution. The hypochlorous acid interacts with sulfhydryl groups in bacterial enzymes. By preventing the activity of these essential enzymes, their basic metabolic reactions are disrupted and results in bacterial death [20]. Moreover, the results of Gutknecht et al.'s study are consistent with our findings. Similarly to the above mentioned study, we found that the single erbium chromium laser did not have a sufficient bactericidal activity [21].

In Charannya et al.'s study, the efficiency of silver nanoparticles in the mentioned study was lower than the present study, which could be attributed to the use of low concentrations $[19,22]$. Also, the size of the nanoparticles in the mentioned study was much larger $(700-300 \mathrm{~nm})$ than that of 


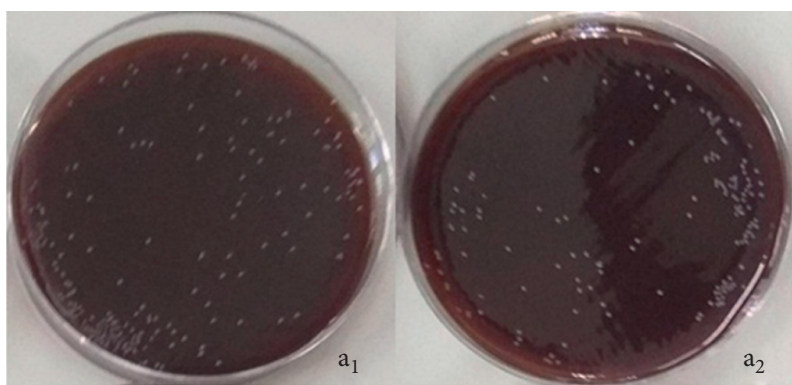

(a)

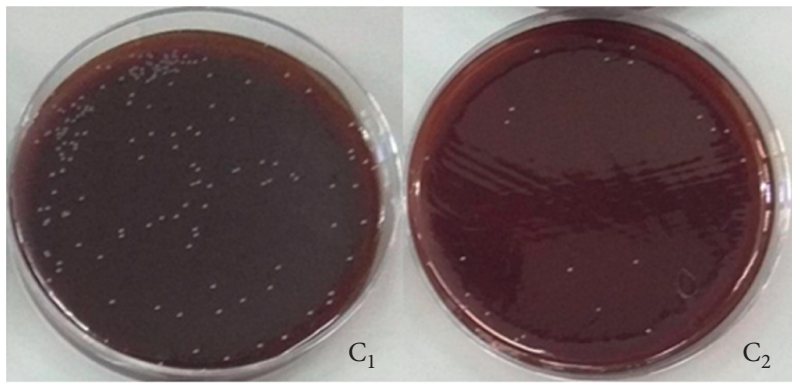

(c)

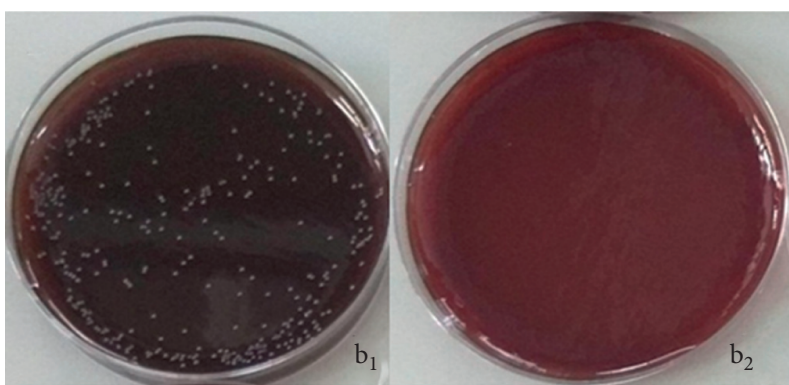

(b)

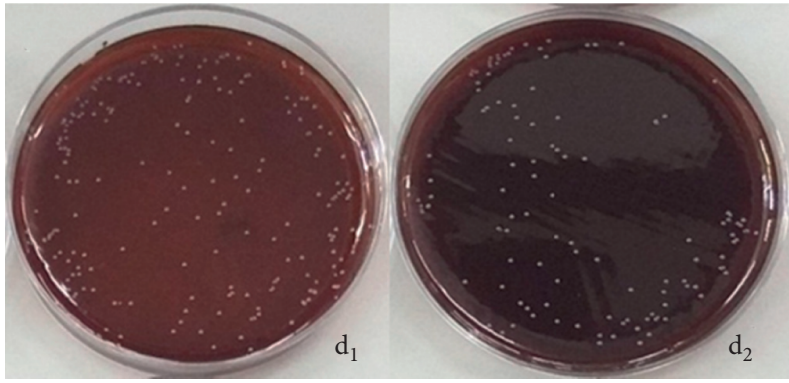

(d)

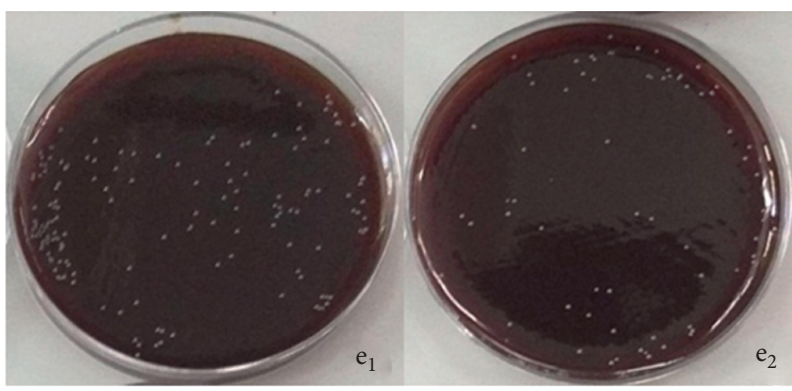

(e)

Figure 4: Bacterial culturing before and after intervention. (a) Negative control, $a_{1}$ before $a_{2}$ after. (b) Hypochlorite sodium, $b_{1}$ before $b_{2}$ after. (c) Nanosilvers, $c_{1}$ before $c_{2}$ after. (d) Erbium chromium laser, $d_{1}$ before $d_{2}$ after. (e) Nanosilvers and erbium chromium laser, $e_{1}$ before $e_{2}$ after.

TABLE 2: Results of Mann-Whitney test with Bonferroni adjustment for comparing the two groups.

\begin{tabular}{lc}
\hline Groups & RCC mean \\
$p_{\text {value }}$ & 0.001 \\
Sodium hypochlorite, negative control group & 0.943 \\
Erbium chromium laser, negative control group & 0.001 \\
Silver nanoparticles, negative control group & 0.102 \\
Erbium chromium laser and silver nanoparticles, negative control group & 0.001 \\
Silver nanoparticles, sodium hypochlorite & 0.001 \\
Erbium chromium laser, sodium hypochlorite & 0.001 \\
Erbium chromium laser and silver nanoparticles, sodium hypochlorite & 0.001 \\
Silver nanoparticles, erbium chromium laser & 0.009 \\
Silver nanoparticles, erbium chromium lasers and silver nanoparticles & 0.152 \\
Silver nanoparticles and erbium chromium laser, erbium chromium laser & \\
\hline
\end{tabular}

the present study $(20 \mathrm{~nm})$. In nanoparticle technology, the smaller particle size leads to a higher specific surface area and hence increases its antibacterial effect [23]. We et al. also reported that the antibacterial efficacy of silver nanoparticles against E. faecalis biofilm depends on the used method with emphasis on concentration and contact time [24].
There was a contradiction regarding the use of silver nanoparticles in cleaning root canals between our findings and the results of We et al.'s study, because the results of $\mathrm{Wu}$ et al.'s study showed that sodium hypochlorite $2 \%$ and $98.2 \%$ reduce the number of Enterococcus faecalis bacterial colonies and silver nanoparticles solution $1 \%$ and $5.6 \%$ decreased the 
bacterial load. But, in the present study, silver nanoparticles acted as a good cleaner and destroyed $83.15 \%$ of Enterococcus faecalis bacterial colonies and the reason for this difference can be the period for which the time solution remains in the root canal mentioned in Wu et al.'s study as 2 minutes while in the present study the silver nanoparticle solution remained in the canal for 5 minutes. Another reason is the percentage of silver nanoparticles solution used with the percent of $1 \%$ and $100 \%$ (pure solution) in $\mathrm{Wu}$ et al.'s and the present study, respectively. Although dentin parts were larger in our study $(14 \mathrm{~mm}$ roots versus dentin parts ( $4 \mathrm{~mm}$ long, $4 \mathrm{~mm}$ wide, and $1 \mathrm{~mm}$ high)), the success of our study was much greater, emphasizing the importance of nanoparticle concentration and time [23, 24], while Xie et al. reported that sodium hypochlorite showed the highest efficiency for cleaning root canals, which is in agreement with our findings [25].

\section{Conclusion}

The results implied that the application of erbium chromium reduced the number of bacterial colonies and there was a difference between before and after laser treatment. But they were not as effective as sodium hypochlorite and did not significantly reduce the number of $E$. faecalis bacteria in the root canals. Moreover, the results demonstrated that the use of single erbium chromium laser and single silver nanoparticle was not sufficient to remove the bacteria from root canal. The use of silver nanoparticle suspension at the desired concentration and appropriate contact time eliminated more bacterial colonies compared with the negative control group. According to the results, it can be concluded that the higher concentrations or high contact times of silver nanoparticles with root canal can be used to achieve better antibacterial effect for cleaning root canals.

\section{Data Availability}

The data can be accessible to the interested researchers by the corresponding authors on reasonable request.

\section{Conflicts of Interest}

The authors declare that they have no conflicts of interest.

\section{Acknowledgments}

This study has been adapted from a M.Sc. thesis at Hamadan University of Medical Sciences (project no. 9510146067).

\section{References}

[1] F. Afkhami, S. Akbari, and N. Chiniforush, "Entrococcus faecalis elimination in root canals using silver nanoparticles, photodynamic therapy, diode laser, or laser-activated nanoparticles: an in vitro study," Journal of Endodontics, vol. 43, no. 2, pp. 279-282, 2017.

[2] U. Schoop, A. Barylyak, K. Goharkhay et al., "The impact of an erbium, chromium:yttrium-scandium-gallium-garnet laser with radial-firing tips on endodontic treatment," Lasers in Medical Science, vol. 24, no. 1, pp. 59-65, 2009.
[3] N. Dewsnup, R. Pileggi, J. Haddix, U. Nair, C. Walker, and C. H. Varella, "Comparison of bacterial reduction in straight and curved canals using erbium, chromium: yttrium-scandium-gallium-garnet laser treatment versus a traditional irrigation technique with sodium hypochlorite," Journal of Endodontics, vol. 36, no. 4, pp. 725-728, 2010.

[4] A. Armand, M. Khani, M. Asnaashari, A. AliAhmadi, and B. Shokri, "Comparison study of root canal disinfection by cold plasma jet and photodynamic therapy," Photodiagnosis and Photodynamic Therapy, vol. 26, pp. 327-333, 2019.

[5] R. Franzen, M. Esteves-Oliveira, J. Meister et al., "Decontamination of deep dentin by means of erbium, chromium: yttrium-scandium-gallium-garnet laser irradiation," Lasers in Medical Science, vol. 24, no. 1, pp. 75-80, 2009.

[6] D. Su, X. Hu, D. Wang, T. Cui, R. Yao, and H. Sun, "Semiconductor laser irradiation improves root canal sealing during routine root canal therapy," PLoS One, vol. 12, no. 9, Article ID e0185512, 2017.

[7] W. Gordon, V. A. Atabakhsh, F. Meza et al., "The antimicrobial efficacy of the erbium, chromium:yttrium-scandiumgallium-garnet laser with radial emitting tips on root canal dentin walls infected with Enterococcus faecalis," The Journal of the American Dental Association, vol. 138, no. 7, pp. 992$1002,2007$.

[8] S. M. Hosseini, B. Zeyni, S. Rastyani et al., "Presence of virulence factors and antibiotic resistances in Enterococcus $\mathrm{sp}$ collected from dairy products and meat," Der Pharmacia Lettre, vol. 8, no. 4, pp. 138-145, 2016.

[9] S. J. Chockattu, B. Deepak, and K. M. Goud, "Comparison of anti-bacterial efficiency of ibuprofen, diclofenac, and calcium hydroxide against Enterococcus faecalis in an endodontic model: an in vitro study," Journal of Conservative Dentistry: JCD, vol. 21, no. 1, p. 80, 2018.

[10] P. González-Luna IV, G.-A. Martínez-Castañón, N.-V. Zavala-Alonso et al., "Bactericide effect of silver nanoparticles as a final irrigation agent in endodontics on Enterococcus faecalis: an ex vivo study," Journal of Nanomaterials, vol. 2016, Article ID 7597295, 2016.

[11] S. Katva, S. Das, H. S. Moti, A. Jyoti, and S. Kaushik, "Antibacterial synergy of silver nanoparticles with gentamicin and chloramphenicol against Enterococcus faecalis," Pharmacognosy Magazine, vol. 13, no. Suppl 4, p. S828, 2017.

[12] J. M. Martinez-Andrade, M. Avalos-Borja, A. R. VilchisNestor, L. O. Sanchez-Vargas, and E. Castro-Longoria, "Dual function of EDTA with silver nanoparticles for root canal treatment-a novel modification," PLoS One, vol. 13, no. 1, Article ID e0190866, 2018.

[13] R. Habibipour, L. Moradi-Haghgou, and A. Farmany, "Green synthesis of AgNPs@PPE and its Pseudomonas aeruginosa biofilm formation activity compared to pomegranate peel extract," International Journal of Nanomedicine, vol. 14, p. 6891, 2019.

[14] S. Kasić, M. Knezović, N. Beader, D. Gabrić, A. I. Malčić, and A. Baraba, "Efficacy of three different lasers on eradication of Enterococcus faecalis and Candida albicans biofilms in root canal system," Photomedicine and Laser Surgery, vol. 35, no. 7, pp. 372-377, 2017.

[15] T. Liu, Z. Huang, Y. Ju, and X. Tang, "Bactericidal efficacy of three parameters of Nd:YAP laser irradiation against Enterococcus faecalis compared with $\mathrm{NaOCl}$ irrigation," Lasers in Medical Science, vol. 34, no. 2, pp. 359-366, 2019.

[16] I. Bago Jurič and I. Anić, "The use of lasers in disinfection and cleaning of root canals: a review," Acta Stomatologica Croatica, vol. 48, no. 1, pp. 6-15, 2014. 
[17] S. E.-D. S. EL-Gendy, S. M. Moussa, A. M. Zaazou, and M. A. Meheissen, "Antibacterial effect of Er, Cr: YSGG laser under various operating conditions in root canals contaminated with Enterococcus faecalis (in vitro study)," Alexandria Dental Journal, vol. 42, no. 1, pp. 108-112, 2017.

[18] A. U. Eldeniz, F. Ozer, H. H. Hadimli, and O. Erganis, "Bactericidal efficacy of Er, Cr: YSGG laser irradiation against Enterococcus faecalis compared with $\mathrm{NaOCl}$ irrigation: an ex vivo pilot study," International Endodontic Journal, vol. 40, no. 2, pp. 112-119, 2007.

[19] K. Halkai, J. Mudda, V. Shivanna, V. Rathod, and R. Halkai, "Antibacterial efficacy of biosynthesized silver nanoparticles against Enterococcus faecalis biofilm: an in vitro study," Contemporary Clinical Dentistry, vol. 9, no. 2, p. 237, 2018.

[20] X. Zeng, S. Xiong, S. Zhuo et al., "Nanosilver/poly (DL-lacticco-glycolic acid) on titanium implant surfaces for the enhancement of antibacterial properties and osteoinductivity," International Journal of Nanomedicine, vol. 14, p. 1849, 2019.

[21] N. Gutknecht, T. S. Al-Karadaghi, M. A. Al-Maliky, G. Conrads, and R. Franzen, "The bactericidal effect of 2780 and $940 \mathrm{~nm}$ laser irradiation onEnterococcus faecalisin bovine root dentin slices of different thicknesses," Photomedicine and Laser Surgery, vol. 34, no. 1, pp. 11-16, 2016.

[22] S. Charannya, D. Duraivel, K. Padminee, S. Poorni, C. Nishanthine, and M. R. Srinivasan, "Comparative evaluation of antimicrobial efficacy of silver nanoparticles and $2 \%$ chlorhexidine gluconate when used alone and in combination assessed using agar diffusion method: an in vitro study," Contemporary Clinical Dentistry, vol. 9, no. Suppl 2, p. S204, 2018.

[23] Y. Dong, H. Zhu, Y. Shen, W. Zhang, and L. Zhang, "Antibacterial activity of silver nanoparticles of different particle size against vibrio natriegens," PLoS One, vol. 14, no. 9, 2019.

[24] D. Wu, W. Fan, A. Kishen, J. L. Gutmann, and B. Fan, "Evaluation of the antibacterial efficacy of silver nanoparticles against Enterococcus faecalis biofilm," Journal of Endodontics, vol. 40, no. 2, pp. 285-290, 2014.

[25] Q. Xie, B. R. Johnson, C. S. Wenckus, M. I. Fayad, and C. D. Wu, "Efficacy of berberine, an antimicrobial plant alkaloid, as an endodontic irrigant against a mixed-culture biofilm in an in vitro tooth model," Journal of Endodontics, vol. 38, no. 8, pp. 1114-1117, 2012. 